\title{
Time-motion analysis and effort-pause relationship in taekwondo combats: a comparison of competitive levels
}

\section{Análise de tempo e movimento e relação esforço pausa em combates de taekwondo: comparação entre níveis competitivos}

\author{
Fabrício Boscolo Del Vecchio1,2 \\ Bruno Antunez \\ Charles Bartel ${ }^{1,2}$
}

Abstract - To improve the combat sports training processes, the knowledge of effort:pause (E:P) ratio and of the high intensity:low intensity (HI:LI) relationship may be useful. However, no studies have investigated these aspects in taekwondo (TKD) official matches from different levels. The aim of this study was to analyze and compare the temporal structure of TKD combat matches at regional and state-level events. Thirty-four combat matches involving male TKD black belt athletes were analyzed. The athletes took part in two separate championships according to their level of competitiveness. Non-parametric distributions were identified in all variables, and the median was used as centrality and the interquartile range (25\%-75\%) for dispersion. The analysis of non-parametric variance, Kruskal-Wallis, with Dunn post-hoc, was used for comparisons between variables within the same competitive level and Mann-Whitney test between them. The significance level was $5 \%$. On both levels, approximately $50 \%$ of combat time $(51.3 \%$ and $50.8 \%$ in state and regional, respectively) was aimed at low-intensity activities in an observation mode; $12 \%$ of the time was devoted to preparation actions; and 36\% represented high-intensity activity. It was also noted that the relationship of E:P at the state level was 1:8; at the regional level, it was 1:4. The relationship of $\mathrm{HI}: \mathrm{LI}$ was $1: 3$ in the state and regional levels. It was observed that there is a difference in the E:P relationship during TKD competitions among different competitive levels. These findings can assist coaches and trainers in developing suitable, specific training processes according to TKD competition level.

Key words: Athletic performance; Martial arts; Physical education and training.

Resumo - Para aperfeiçoar o processo de treino em modalidades esportivas de combate, é relevante o conhecimento das relaçóes esforço:pausa (E:P) e alta intensidade:baixa intensidade (AI:BI). Porém, não há estudos investigando essas relações comparando diferentes níveis competitivos no taekwondo (TKD). Objetivou-se analisar e comparar açôes de tempo movimento e combates de TKD de diferentes niveis competitivos. Foram analisados 34 combates de atletas faixas pretas de TKD do sexo masculino em dois campeonatos de niveis competitivos distintos. Foi identificada distribuição não paramétrica dos dados para todas variáveis, portanto, adotou-se mediana e semiamplitude interquartílica (25\%-75\%) para a dispersão. Para comparação das variáveis no mesmo nível competitivo utilizou-se análise de variância Kruskal-Wallis com post-hoc de Dunn e teste de Mann-Whitney para comparação entre niveis competitivos. O nivel de significancia foi de 5\%. Nos dois niveis, aproximadamente 50\% $151.3 \%$ e $50.8 \%$ em nivel estadual e regional, respectivamente) do tempo de combate é destinado aos blocos de observação, $12 \%$ às açôes de preparação, ambos esforços de baixa intensidade, e $36 \%$ às ações de interação, em alta intensidade. A relação E:P em nivel estadual foi de 1:8 e em nivel regional de 1:4. Já a relação AI:BI foi de 1:3 nos niveis estadual e regional. Existe diferença entre niveis competitivos para as relação E:P. Os presentes achados podem auxiliar técnicos e preparadores físicos no processo de prescrição e aplicação do treinamento específico, podendo utilizar-se a temporalidade de acordo com o nivel competitivo dos atletas.

Palavras-chave: Artes marciais; Desempenho atlético; Educação física e treinamento.

1 Universidade Federal de Pelotas. Escola Superior de Educação Física. Pelotas, RS. Brasil.

2 Grupo de Estudos e Pesquisas em Treinamento Esportivo e Desempenho Físico. Universidade Federal de Pelotas.

Received: 10 June 2016 Accepted: 14 December 2016 


\section{INTRODUCTION}

Taekwondo (TKD) is a Korean combat sport, an official sports in the Olympic Games since 2000. In TKD matches, athletes apply kicks to the thorax and head, as well as punches to the thorax ${ }^{1}$. In general, official matches have three two-minute rounds, with one minute between them. Simulated TKD matches are predominantly aerobic, which contributes close to $66 \%$ of energy demand, while anaerobic alatic and lactic contribute $30 \%$ and $4 \%$, respectively ${ }^{2}$. In official matches, the heart rate can reach $197 \pm 2 \mathrm{bpm}^{3}$, with a blood lactate concentration of $12.2 \pm 4.6 \mathrm{mmol} . \mathrm{L}^{-14}$. Additionally, official matches promote an increase in cortisol concentration, a hormone secreted during stressful situations, as observed in TKD combats 5 . To improve the physical fitness of TKD athletes with specific stimuli, it is necessary to know the combat structure of different competitive levels.

A better understanding of the variables that can contribute to the training process at higher competition level of combat sports can increase the chance of success ${ }^{6}$, especially considering their agonistic characteristics ${ }^{7}$. To ameliorate the training process and make it more specific, the effort:pause (E:P) ratio is one of the variables of the notational analysis that may contribute in the development of specific tasks used to the athlete's metabolic conditioning ${ }^{8}$. In general, the methods of data assessment consider only isolated information that could be registered as simple E: $\mathrm{P}^{8}$. In order to conduct detailed analyses, researchers are investigating the effort type (as punches, kicks or throws) $)^{8,9}$, intensity (as high or low) ${ }^{10}$, and the characteristics (as observation, preparation and interaction) ${ }^{9,11}$. However, to date we found no studies that conducted a notational analysis of different competitive levels in official TKD matches.

Considering the characteristics of time structure, three effort levels can be identified - observation, preparation and interaction, which were used in muaythai ${ }^{12}$, kickboxing ${ }^{11}$ and karate ${ }^{7}$. Such an analytical strategy provides relevant information about the combat's intensity ${ }^{7}$. In general, TKD has an E:P ratio from $1: 3^{13}$ to $1: 7^{2}$, and the combat sequences last approximately $25 \mathrm{~s}$. TKD matches performed by young black belts had observation efforts lasting around $6.4 \pm 2.1 \mathrm{~s}$ and interaction efforts last in around $2.8 \pm 1.1 \mathrm{~s}^{1}$. Bridge et al., (2011) investigated international black belt adult athletes and found observation efforts lasting around $3.1 \pm 1.0 \mathrm{~s}$, preparation efforts lasting from $7 \pm 1.7 \mathrm{~s}$ to $9.7 \pm 5.7 \mathrm{~s}$, and interaction efforts lasting around $1.7 \pm 0.4 \mathrm{~s}$. In a two-minute round, TKD athletes perform non-attack actions like stepping for approximately 79s, with 10 s of interaction like kicks and punches, and around 30s between efforts ${ }^{2}$.

Previous studies found a wide variability in the results from notational analysis - especially in the technical-tactical aspects. The variability was related to differences in age, gender and competitive level ${ }^{8}$. Therefore, the results from one combat sport cannot be transferred to another, because the $\mathrm{E}: \mathrm{P}$ ratio is modality-dependent. There is a large amount of research examining E:P and others time-motion characteristics in combat sports, 
including a recent article that showed differences between competitive phases in a national level muaythai championships. ${ }^{12}$ However, no studies have investigated time-motion in TKD matches of different competitive levels. This research subject is important because differences in physical fitness and movement patterns between levels may directly influence the time-motion action and the temporal structure, and affect the training organization. In this context, this study aims to analyze and compare the temporal structure of TKD matches of different competitive levels. Our hypothesis is that differences exist in temporal structure across different competitive levels, and that the lower level event exhibits lower E:P ratio, because athletes with lower competitive level apply higher number of techniques and, consequently, spend more time in effort actions, independently of the intensity ${ }^{1,12}$.

\section{METHODOLOGICAL PROCEDURES}

\section{Study profile and characterization of variables}

The study investigated time-motion actions from TKD combats and was previously approved by Local Ethics Committee (\#445.796). The dependent variables were combat time during observation, preparation and interaction levels, as well as non-combat time during card request, medical care, and unjustified pauses. The competition level was considered the main independent variable.

\section{Subjects and study sample}

The sample was composed of 34 combat matches performed by male black belt TKD athletes from Federação Gaúcha de Taekwondo (FGT) in Brazil. These combatants were at least 18 years old and took part in at least one competitive event in the last year.

Two championships of different competition levels were recorded. The first championship (level 1) was the Taekwondo Mercosul Cup, a regional level competition held in Pelotas - Rio Grande do Sul/RS, where 13 matches were analyzed. The second championship (level 2), a state-level event conducted in Sapucaia do Sul - RS, was a qualifying championship to compose the Rio Grande do Sul TKD Team, where 21 matches were analyzed. These events, held one month apart, were chosen according to the wide difference between the competitive level of the combatants, as well as for their convenient schedule and geography.

Both competitions were supervised by the Brazilian Taekwondo Confederation, which allowed the recording of the combats and the development of this study. The state-level combats followed World Taekwondo Federation (WTF) rules, with three 2 min rounds, and the regional level matches followed the competitive rules set by the event organization, in which all combats were composed of two 2 min rounds, a procedure allowed by WTF. 


\section{Study settings}

Access to the competitions was authorized by the FGT. The video camera was positioned on a mobile tripod $3 \mathrm{~m}$ from the combat area and was controlled by a Taekwondo researcher with 10 years of experience. These strategies were adopted to ensure that there was no loss of the athletes framing in the video during the combat, and to provide the best position for future identification of motor gestures in computer software.

After placing the tripod into a specific position covering the combat area and the combat control table, the combats were stored on an $8 \mathrm{~GB}$ Kingston SD memory card using a Sony DSC-40 camera recorder. After this, the videos were transferred to a portable computer for later analysis through the Kinovea software, which is a computer program capable of controlling the videos speed execution and offers several features for analysis, such as instant zoom, slow motion, and timers linked to the editing screen ${ }^{6}$.

\section{Procedures Analysis}

The evaluator responsible for the video analysis has a degree in physical education and a black belt in TKD, with previous experience in TKD competitions as well as in this kind of study. In present study, the objectivity and reproducibility were not directly tested, but the same procedure was previously adopted analyze competitions of mixed martial arts, muaythai and karate, and the coefficient of intra-class correlation (ICC) was higher than $0.9^{10,12}$ for preparatory activities, time of combat and time of pause. In general, time and motion analysis (TMA) present high reproducibility ${ }^{14}$. Using the same procedure with TKD matches, our research group found ICC from 0.86 - in observation phase - to 0.99 in interaction phase. The structural analysis of the combats was analyzed to identify the following variables:

\section{Macro structural time-motion variables}

Total combat time is the period between the sound signal to start the combat and the signal to end combat ${ }^{14}$. For both competitive events, the two 2-minute rounds and the 1-minute recovery time between them were considered in the statistical analysis.

Breaking time comprises the period between rounds. In this time, the athletes reduce oxygen uptake, the heart rate diminishes, providing a physiological recovery lasting nearly $60 \mathrm{~s}^{14}$.

Round duration is the period that corresponds to the sound signal to start each round until the ending signal of the round. We chose not to use the default time set by the official rule due to variations in the measurement of time. It is important to highlight that timing is interrupted for medical care, card application, or unjustified pauses.

\section{Microstructural time-motion variables}

The microstructural variables ${ }^{7,11,12}$ are:

- Observation time: the period that athletes are studying each other 
during the combat, with low intensity movement execution (steps) and without offensive characteristics.

- Preparation time: the situation identified by the application of isolated moves, which have the primary intention to adjust the distance from the opponent and provide settings for execution of subsequent attacks with greater intensity.

- Interaction time: is the moment in which athletes are actually fighting and exchanging successive sets of kicks, either to score or to disable the opponent to continue the match.

\section{Other time-motion variables established by World Taekwondo Federation}

Based on WTF rules, matches are temporarily interrupted in the following situations.

- Card request: The card request occurs when coaches show a card soliciting a pause during the combat to conduct a video analysis of questionable points scored and computed by the referee or by the electronic system.

- Medical care: represents a moment during the combat when the referee authorizes the medical assessment of one or both athletes.

- Unjustified pause: any moment during the combat characterized by a disruption of fighting progress without a clear reason. This pause is primarily intended to restore clothing and protective garments like the vest, helmet, and other protectors to their correct position during the combat.

\section{Statistical analysis}

The Shapiro-Wilk normality test was applied for data analysis, but it did not find any parametric distribution in the variables. Thus, we opted to adopt the medians a centrality and the interquartile range (25\%-75\%) for dispersion.

The Kruskal-Wallis analysis of variance to non-parametric data, with Dunn post-hoc, was conducted to compare variables within the same competitive level. The Mann-Whitney test was applied to compare the same variable between two competitive levels. Due to the intermittency and unpredictability of the fighting, which provides different frequencies of occurrence, only the variables with more than five records were considered in the analysis. A value of $\mathrm{p} \leq 0.05$ was adopted as the level of statistical significance. To calculate the effect size (ES), firstly was found the $r$-value due the equation $r=$. After that, Cohen's $d$ was calculated $d$ $=$, and values near 0.2 were considered as small effect, around 0.5 were considered medium, and higher than 0.8 was considered as large effect ${ }^{13}$.

\section{RESULTS}

The combat macrostructure and other time-motion structures set by WTF are presented in Table 1 . There was a significant difference in the duration 
of the first round between the two levels of competition $(z=3.42, p<0.001$, $\mathrm{ES}=1.44$ ), but there was no difference in the other analyzed variables.

Table 1. Macro structural time-motion analysis in Taekwondo matches from different competitive level.

\begin{tabular}{lll}
\hline & Regional Level $(\mathrm{n}=13)$ & State Level $(\mathrm{n}=21)$ \\
\hline First-round duration $(\mathrm{s})$ & $223(182-309)$ & $138(123-171)^{\star}$ \\
Break between rounds $(\mathrm{s})$ & $49.5(47.1-58.7)$ & $46.2(43-51)$ \\
Second round duration $(\mathrm{s})$ & $218(184.1-243)$ & $157(122-211)$ \\
Card request (s) & $34.3(22.6-48.3)$ & $49.7(31.2-59.6)$ \\
Medical care (s) & $26.9(20.8-32.3)$ & $32.8(16.5-50.2)$ \\
Unjustified pauses (s) & $19.7(16.2-28.2)$ & $11.2(6.3-16.6)$ \\
\hline
\end{tabular}

* Statistically different from regional level $(z=3.42 ; p<0.001)$

Table 2 shows that, in both levels of competition and considering the sum of rounds, approximately $50 \%$ of the combat time $(51.3 \%$ and $50.8 \%$ in the state and regional levels, respectively) was aimed at low-intensity actions, $13 \%$ of the time was spent on preparation, and $37 \%$ of the time was dedicated to high intensity fighting.

Table 2. Number (occurrence) and percentage (\%) of the types of action, by round and according to the competitive level.

\begin{tabular}{lccc}
\hline Time-motion Microstructure & Round & Regional Level $(\mathrm{n}=13)$ & State Level $(\mathrm{n}=21)$ \\
\hline Observation & 1 & $202(31.2 \%)$ & $232(26.3 \%)$ \\
Observation & 2 & $150(20.1 \%)$ & $216(24.5 \%)$ \\
Preparation & 1 & $55(8.5 \%)$ & $52(5.9 \%)$ \\
Preparation & 2 & $26(4.1 \%)$ & $60(6.8 \%)$ \\
Interaction & 1 & $133(20.5 \%)$ & $165(18.6 \%)$ \\
Interaction & 2 & $101(15.6 \%)$ & $159(17.9 \%)$ \\
Total & & $667(100 \%)$ & $884(100 \%)$ \\
\hline
\end{tabular}

As shown in Table 3, the state level combats displayed a large duration for the observation efforts in the second round $(Z=9.38, \mathrm{p}<0.001, \mathrm{ES}=$ 3.3), but not in the first round $(Z=0.26, p=0.79, E S=0.09)$. Considering the Preparation level, Regional matches showed higher average time spent in preparation in the first $(Z=7.32, \mathrm{p}<0.001, \mathrm{ES}=2.59)$ and second round $(Z=6.17, p<0.001, E S=2.19)$. No differences in the interaction phase of the first round were recorded between the two levels of competition $(Z=$ $0.2, p=0.84, E S=0.06)$. However, the state level matches showed shorter interaction efforts in the second round $(\mathrm{Z}=3.05, \mathrm{p}<0.01, \mathrm{ES}=1.22)$.

Table 3 shows the median and 25\%-75\% of average time in different rounds and levels of competition in TKD matches. The average time spent in the observation phase was higher in round 1 compared to round 2 at the regional level $(\mathrm{p}<0.05)$, but not at the state level. In both rounds of state level matches, less average time was spent in the preparation phase than in the observation phase ( $\mathrm{p}<0.05$ for both rounds). In regional level matches, this difference was found only in the second round $(\mathrm{p}<0.05)$.In 
matches of both competitive levels, the average interaction time was lower than observational actions in the first round (both with $\mathrm{p}<0.05$ ), but this distinction was only maintained in the second round of state level matches $(\mathrm{p}<0.05)$. During the second round, the average interaction average was higher than the average observational time in the regional level matches $(\mathrm{p}<0.05)$, but lower at the state level matches $(\mathrm{p}<0.05)$. The average time of interactions was higher than the time dedicated to preparation actions during the second round of state level matches $(\mathrm{p}<0.05)$.

Table 3. Time-motion TKD variables in real combats, considering type of effort, round and competitive level.

\begin{tabular}{|c|c|c|c|c|c|c|}
\hline & \multicolumn{2}{|c|}{ Observation } & \multicolumn{2}{|c|}{ Preparation } & \multicolumn{2}{|c|}{ Interaction } \\
\hline & Round 1 & Round 2 & Round 1 & Round 2 & Round 1 & Round 2 \\
\hline \multicolumn{7}{|c|}{ Regional level $(n=13)$} \\
\hline Ocurrences (n) & 202 & 130 & 55 & 26 & 133 & 101 \\
\hline Average time (s) & $5.6(3-9.5)$ & $2.6(1.5-4.2)^{\star}$ & $5.8(2.1-12.1)$ & $2.9(2.4-3.6)^{\#}$ & $2.3(0.9-8.6)^{\star \S}$ & $3.3(2.2-5.6)^{\#}$ \\
\hline \multicolumn{7}{|l|}{ State level $(n=21)$} \\
\hline Ocurrences (n) & 232 & 216 & 52 & 60 & 165 & 159 \\
\hline Average time (s) & $5.6(3.2-10.5)$ & $6.6(3.5-10.4)$ & $0.8(0.6-1.4)^{\star \#}$ & $1.0(0.8-1.3)^{\star \#}$ & $2.7(1.7-3.6)^{*} \S \dagger$ & $3.1(1.6-4.1)^{\star \# \S \dagger}$ \\
\hline
\end{tabular}

*Different from Round1 - Observation; \#: Different from the Observation average time in the Round 2; §: Different from the Round1 Preparation; †: Different from the values of Round 2 - Preparation, $p \leq 0.05$ was adopted as a level of statistical significance.

The E:P ratio is determined by classifying the combat actions of observation, preparation, and interaction as Effort (E), and the interruption time during the combat (card, medical, and unjustified breaks, as shown in Table 1) as Pause (P). Results showed a wide difference in the E:P ratio. At the state level, the E:P was 1:8, and it reached 1:4 at the regional level.

\section{DISCUSSION}

This study aimed to investigate the temporal pattern of TKD matches in regional and state-level competitions. As noted in our hypotheses, we found statistically significant differences between levels for most variables. The main results were: 1 ) a wide difference in the three effort levels of observation, preparation, and interactionand 2) higher pause moments in state-level matches (E:P of 1:8) in comparison to those in regional-level matches (E:P of 1:4). Additionally, it was observed that the observation time in the second round was higher at state level matches; in both rounds, the preparation time was higher in regional matches; and the interaction time in the second round was higher in regional matches. To the best of our knowledge, this is the first study that analyzed the temporal characteristics of official TKD matches. Corroborating our findings, a previous study of Muaythai matches showed that the observation time was higher in finals matches than in qualifier matches. It was assumed that this pattern was likely due to the superiority of the fighters whoreached the finals ${ }^{7}$. Something similar was found in the present study, as statelevel athletes, supposedly with higher level, spent more time than regional level athletes in efforts characterized as observational during the second round. 
Other studies pointed out that, at certain moments of the combat, it is common for athletes choose to take more time studying the opponent's fighting style to avoid unexpected attacks from their opponents ${ }^{14}$. Therefore, the time devoted to this type of action is dependent on the competitive level. Athletes from regional level matches spent more time on preparation and interaction level actions than athletes from state level. This could be due to the fact that athletes from lower level tend to apply more techniques to obtain success in scoring ${ }^{1}$. Furthermore, it is important to point that the regional level matches had two rounds, and the state level had three rounds, which could affect the temporal profile. However, it is important to say that the World Taekwondo Federation allow this kind of adjustment in its events.

The results show an E:P ratio of 1:8 at the state level and 1:4 at regional level matches. Previously, a high number of studies related different values to grappling combat sports, reporting ratios near 2:1 for judo ${ }^{8}$, 6:1 to 9:1 in brazilian jiu jitsu ${ }^{16}$, and almost 2:1 in greco-roman wrestling ${ }^{17}$. Previous studies have reported E:P ratio of 1:3 to 1:4 in Olympic TKD ${ }^{1}$ and 1:6 to Songham $\mathrm{TKD}^{18}$, and this variability may be associated with differences in the TKD styles, because upper limb blows are not allowed in Songham ${ }^{18}$ combats, lowering the number of permitted techniques.

When the observation and preparation levels were grouped as lowintensity (LI) effort and the interaction level was considered high-intensity effort (HI), the values obtained in this study were 1:3 in state and regional level matches. In other words, the differences in values decreased between competitive levels, indicating that, despite the differences in effort duration, the HI:LI ratio was similar. Previous studies found that the HI:LI ratio of TKD competitors at the national and international level was approximately $1: 7^{19}$. However, muaythai competitors at the national level and international kickboxing athletes showed 1:2 to 1:3 ratio and 1:1 ratio, respectively ${ }^{12,14}$. In general, most TKD matches are decided in the last round ${ }^{20,21}$ and this aspect should be considered in the next thematic studies. As limitations, we can point out the difference in the number of rounds, which were three versus two in the state- and regional-level events, respectively, but we only used information from two rounds in all matches. The absence of better characterizations of the athletes - such as age, time of practice, height and weight may be another limitation, but these variables have secondary relevance during the combat time, especially due to the range of ages (18 to 29 years) and the weight categories. However, the authors suggest that new studies consider the influence of rule changes in time-motion analysis and the differences between gender, age and weight categories, considering these three effort levels.

This present study is relevant for training process athletes; coaches can use specific exercises considering temporality here observed. As a recommendation, we encourage coaches to perform training sessions with high and low intensity as well, considering the competitive level of each athlete when distributing the training loads, including specifically exercise with 
6s observation, 1s preparation and 3s interaction for state level and $4 \mathrm{~s}$ observation, $4 \mathrm{~s}$ preparation and $3 \mathrm{~s}$ interaction for regional level.

\section{CONCLUSION}

According to the results, the duration of first rounds was longer in regionallevel combats. Approximately $50 \%$ of the combat time is dedicated to lowintensity actions, $13 \%$ of the time was spent on preparation, and $37 \%$ of the time is spent on high intensity actions. State level matches have longer observation phases, but the preparation and interaction activities are longer in regional level matches. A greater amplitude of $\mathrm{E}: \mathrm{P}$ was found in higher level matches and HI:LI is similar between groups. Finally, different competitive level TKD matches show dissimilar temporal structure. This difference may be associated with modification in technical-tactical standards.

\section{REFERENCES}

1. Tornello F, Capranica L, Chiodo S, Minganti C, Tessitore A. Time-motion analysis of youth Olympic Taekwondo combats. J Strength Cond Res 2013;27(1):223-8.

2. Campos FAD, Bertuzzi R, Dourado AC, Santos VGF, Franchini E. Energy demands in taekwondo athletes during combat simulation. Eur J Appl Physiol 2012;112(4):1221-8.

3. Bouhlel L, Jouni A, Gmada N, Nefzi A, Abadía KB, Tabka Z. Heart rate and blood lactate responses during Taekwondo training and competition. Sci Sports 2006;22(5):285-90.

4. Bridge CA, McNaughton LR, Close GL, Drust B. Taekwondo exercise protocols do not recreate the physiological responses of championship combat. Int J Sports Med 2013;34(7):573-81.

5. Chiodo S, Tessitore A, Cortis C, Cibelli G, Lupo C, Ammendolia A, De Rosas M, Capranica L. Stress Stress-related hormonal and psychological changes to official youth Taekwondo competitions. Scand J Med Sci Sports 2011;21(1):111-9.

6. Franchini E, Del Vechhio FB. Estudos em modalidades esportivas de combate: estado da arte. Rev Bras Educ Fís e Esporte 2011;25(suppl 1):67-81.

7. Arriaza R. Karate. In: Kordi R, Maffulli N, Wroble RR, Wallace WA, editores. Combat Sports Medicine. London: Ed. Springer-Verlag; 2009. p. 287-298.

8. Miarka B, Panissa V, Julio UF, Del Vecchio FB, Calmet M, Franchini E. A comparison of time-motion performance between age groups in judo matches. J Sports Sci 2012;30(9):899-905.

9. Bridge CA, Jones MA, Drust B. The activity profile in international Taekwondo competition is modulated by weight category. Int J Sport Physiol Perform 2011;6(3):344-57.

10. Del Vechhio FB, Hirata SM, Franchini E. A review of time-motion analysis and combat development in Mixed Martial Arts matches at regional level tournaments. Percept Mot Skills 2011;112(2):639-48.

11. Silva JJR, Del Vecchio FB, Picanço LM, Takito MY, Franchini E. Time-Motion analysis in Muay-Thai and Kick-Boxing amateur matches. J Hum Spo Exerc 2011;6(3):1-7.

12. Del Vecchio FB, Silva JJR, Farias CB. Análise temporal de combates de Muay-Thai de nível nacional: efeitos da fase competitiva. Rev Art Marc Asiat 2015;10(1):34-41.

13. Rosenthal R. Meta-analytic procedures for social research. California: SAGE Publication; 1991. 
14. Ouergui I, Hssin N, Haddad M, Franchini E, Behm D, Wong P, et al. Time motion analysis of international kickboxing competition. J Strength Cond Res 2014;28(12):3537-43.

15. Chaabène H, Franchini E, Miarka B, Selmi MA, Mkaouer B, Chamari K. Time-Motion Analysis and Physiological Responses to Karate Official Combat Sessions: Is There a Difference Between Winners and Defeated Karatekas? Int J Sports Physiol Perform 2014;9(2):302-8.

16. Andreato LV, Julio UF, Gonçalves Panissa VL, Del Conti Esteves JV, Hardt F, Franzói de Moraes SM, et al. Brazilian jiu-jitsu simulated competition Part II: Physical performance, time-motion, tactical analyses and perceptual responses. J Strength Cond Res 2015;29(7):2015-25.

17. Nilsson J, Csergö S, Gullstrand L, Tveit P, Refsnes PE. Work-time profile, blood lactate concentration and rating of perceived exertion in the 1998 Greco-Roman wrestling World Championship. J Sport Sci 2002;20(11):939-45.

18. Matsushigue KA, Hartmann K, Franchini E. Taekwondo: Physiological responses and match analysis. J Strength Cond Res 2009;23(4):1112-7.

19. Heller J, Peric T, Dlouhá R, Kohliková E, Melichna J, Nováková H. Physiological profiles of male and female taekwon-do (ITF) black belts. J Sport Sci 1998;16(3):243-9.

20. Santos VGF, Franchini E, Lima-Silva AE. Relationship between attack and skipping in Taekwondo contests. J Strength Cond Res 2011;25(6):1743-51.

21. Kazemi M, Waalen J, Morgan C, White AR. A profile of Olympic taekwondo competitors. J Sports Sci Med 2006;5(CSSI):114-21.

\section{CORRESPONDING AUTHOR}

Charles Bartel

Rua Póvoas Júnior, 517 - Três Vendas, Pelotas - RS, Brasil. CEP: 96055-680

E-mail: cbartelf@gmail.com 